\title{
Hospitality training as a means of independence for young adults with learning disabilities
}

\section{Alison Mclntosh and Candice Harris}

Dr Alison McIntosh joined AUT as professor of hospitality and tourism in February 2017. Her research focuses on issues of social justice and advocacy through tourism and hospitality in the pursuit of social change. Her recent work examines accessible travel, and hospitality training and employment for people with disabilities.

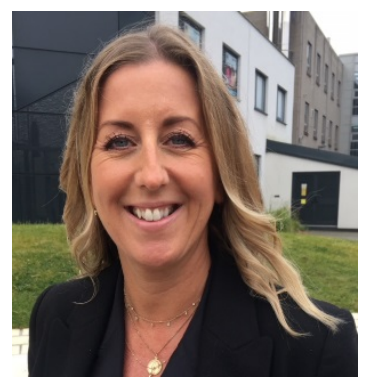

Dr Candice Harris is a professor of management and head of department (Management) in the Faculty of Business, Economics and Law at AUT. Her main areas of research are careers and gendered experiences of work (paid and unpaid).

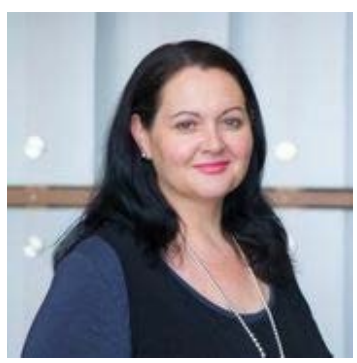

Employment is a core plank of independent living for people with disabilities and a key part of their identity and self-esteem. Nevertheless, it is widely recorded that people with disabilities have lower employment rates than the nondisabled, and continue to experience workplace discrimination. Workers with disabilities are generally found to have greater loyalty to the company, punctuality to the job, dependability, greater levels of cooperation and dedication, and lower turnover rates and absenteeism. Representing an estimated 10-19 percent of the general population worldwide, people with disabilities are seen as an untapped source of workers for hospitality labour [1]. Yet evidence shows that the hospitality industry has, so far, been a follower rather than a leader with respect to training and employment practices for people with disabilities compared to other industries [2]. Viewing disability as a product of the disabling wider social and attitudinal barriers around disability (known as the social model of disability [3]), there is an opportunity for the hospitality industry to contribute toward positive social change.

Given the need to change negative societal attitudes before there can be an increase in the employment of people with disabilities, there is an important need to examine representations of disability in hospitality training and employment. Representations are important because they set expectations around behavioural norms and can help break down barriers by influencing the perceptions of those who receive them. Applying a constructionist approach [4], this research examined how hospitality work and training is represented in the popular television documentary series The Special Needs Hotel as it relates to training for young adults with learning disabilities ${ }^{1}$ - a group who are rendered more marginalised in employment than any other group of young people with disabilities. The three-part TV series, which aired on TVNZ in 2017, followed the experiences of young people with learning disabilities as they received hands-on hospitality training at the Foxes Hotel and Academy - a specialist catering college and residential training hotel in Somerset, U.K., that is also a fully operating hotel with paying guests (http://foxesacademy.ac.uk/). Over their three years of study, learners are trained in three vocational departments - house-keeping, food preparation and food service - before being prepared to apply for and seek hospitality employment.

The research found that the series positively presents hospitality training as a means of enjoyment and of 'achieving independence' for the young adults with learning disabilities, with coping strategies and accommodations used to ensure 
the learners meet the necessary 'realistic expectations' and requirements of hospitality work. Through the intensive hands-on training, the learners are found to successfully acquire life skills, gain independence, find hospitality employment, and make plans for the future. However, this positive representation contrasts with the fear and realities of independence and struggles with the pressures of hospitality work for the trainees themselves (struggles that are both emotional and physical due to the nature of their disability). Our research highlighted that not all learners wanted independence, and often struggled with the training; for example, the stress and speed of service delivery, difficulties in communicating with customers, and having to work alone.

Lessons from this research provide the opportunity to review and vary what is expected of the 'look and feel' of hospitality work and service delivery in order to increase employment for people with disabilities. In particular, if left unchallenged, the stereotyping of the 'professionalism' expected in hospitality work and training can render people with learning disabilities as being and looking unprofessional as hospitality workers and requiring accommodation to meet the standards of 'doing hospitality'. There is a need to give greater attention to disability awareness training, including information geared toward working alongside employees with disabilities, and HR practices. There are challenges to employers about their attitudes toward employing people with disabilities and management of the physical and service environment with regards to how they can render it welcoming or unwelcoming for employees with disabilities. Above all, this understanding can open opportunities to review and realign hospitality employment and training with ethical and non-discriminatory principles and guidelines, which are essential if the employment of people with disabilities is to be improved. As this research concluded, the inclusion of people with disabilities can make the hospitality experience more diverse, personal, meaningful, unique and memorable.

The full research article can be accessed

here: https://www.sciencedirect.com/science/article/pii/S0278431917307351

\section{Note}

1. We use the terminology of the documentary series and recognise the varied, unique and highly complex nature of learning disabilities.

\section{Corresponding author}

Alison McIntosh can be contacted at: alison.mcintosh@aut.ac.nz

\section{References}

(1) Poria, Y.; Reichel, A.; Brandt, Y. Dimensions of Hotel Experience of People with Disabilities: An Exploratory Study. International Journal of Contemporary Hospitality Management 2011, 23(5), 571-591.

(2) Groschl, S. Current Human Resources Practices Affecting the Employment of Persons with Disabilities in Selected Toronto Hotels. International Journal of Hospitality and Tourism Administration 2004, 5(3), 15-30.

(3) Oliver, M. Understanding Disability: From Theory to Practice; Palgrave Macmillan: Basingstoke, U.K., 1996.

(4) Hall, S. Representation: Cultural Representations and Signifying Practices; Sage: London, U.K., 1997. 